\title{
- Carotenoid Production Process Using Green Microalgae of the 2Dunaliella Genus: Model-Based Analysis of Interspecies Variability
}

\author{
${ }_{3}$ Melanie Fachet, ${ }^{\dagger}$ Robert J. Flassig, ${ }^{\dagger}$ Liisa K. Rihko-Struckmann, ${ }^{*}{ }^{\dagger} \odot$ and Kai Sundmacher ${ }^{\dagger,}$ \\ $4{ }^{\dagger}$ Process Systems Engineering, Max Planck Institute for Dynamics of Complex Technical Systems, Magdeburg, 39106, Germany \\ 5 Process Systems Engineering, Otto von Guericke University Magdeburg, Magdeburg, 39106, Germany
}

6

Supporting Information

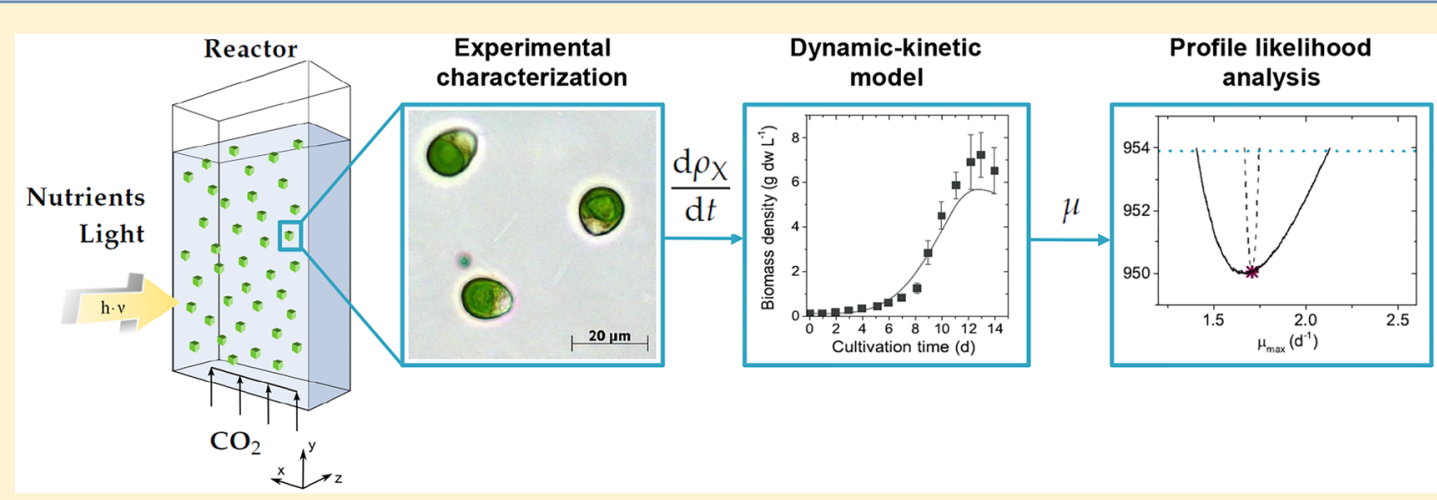

7 ABSTRACT: The engineering of photosynthetic bioprocesses is associated with many hurdles due to limited mechanistic knowledge and inherent biological variability. Because of their ability to accumulate high amounts of $\beta$-carotene, green microalgae of the Dunaliella genus are of high commercial relevance for the production of food, feed, and high-value fine chemicals. This work aims at investigating the interspecies differences between two industrially relevant Dunaliella species, namely D. salina and D. parva. A systematic work flow composed of experiments and mathematical modeling was developed and applied to both species. The approach combining flow cytometry and pulse amplitude modulation (PAM) fluorometry with biochemical methods enabled a coherent view on the metabolism during the adaptational stress response of Dunaliella under carotenogenic conditions. The experimental data was used to formulate a dynamic-kinetic reactor model that covered the effects of light and nutrient availability on biomass growth, internal nutrient status, and pigment fraction in the biomass. Profile likelihood analysis was performed to ensure the identifiability of the model parameters and to point out targets for model reduction. The experimental and computational results revealed significant variability between $D$. salina and $D$. parva in terms of morphology, biomass, and $\beta$-carotene productivity as well as differences in photoacclimation and photoinhibition. The synergistic approach combining experimental and mathematical methods provides a systems-level understanding of the microalgal carotenogenesis under fluctuating environmental conditions and thereby drive the development of sustainable and economically feasible phototrophic processes.

\section{INTRODUCTION}

23 Halotolerant green microalgae of the Dunaliella genus are 24 among the most important production organisms for natural $\beta$ 25 carotene. The accumulation of the pigment is an adaption of 26 the exposure to extreme environmental conditions such as high 27 light intensity, high salinity, and nutrient starvation. The 28 overaccumulation of carotenoid pigments is due to a stress 29 response which enables Dunaliella to survive in hypersaline 30 environments. Dunaliella sp. occur in saline shallow lakes and 31 evaporation ponds all over the world. ${ }^{1}$ Beside hypersaline 32 species in the genus Dunaliella several euryhaline species of 33 Dunaliella (e.g., D. tertiolecta and D. primolecta have been 34 reported, which grow in marine water. However, only the 35 hypersaline species of the Dunaliella genus (e.g., D. parva, D. 36 viridis, and $D$. salina) play an important role in algal mass 37 cultivation. $^{2}$
There have been very few studies dealing with a comparative 38 evaluation of physiological and biochemical differences among 39 microalgal strains or species. However, when they exist they 40 generally indicate a significant intra- and interspecies variability 41 which makes comparison of results and deduction of valuable 42 conclusions challenging among different strains. ${ }^{3}$ Because of its 43 high $\beta$-carotene content, the majority of the studies focused on 44 the biotechnological potential of $D$. salina. This work aims at 45 investigating the interspecies differences between two carote- 46 nogenic Dunaliella strains, namely D. salina and D. parva. A 47

Special Issue: Tapio Salmi Festschrift

Received: April 20, 2017

Revised: June 26, 2017

Accepted: July 5, 2017

Published: July 5, 2017 


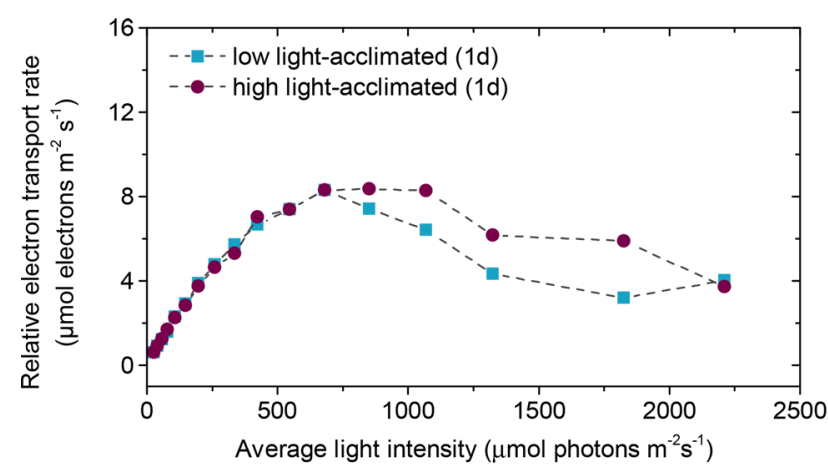

(a) D. salina

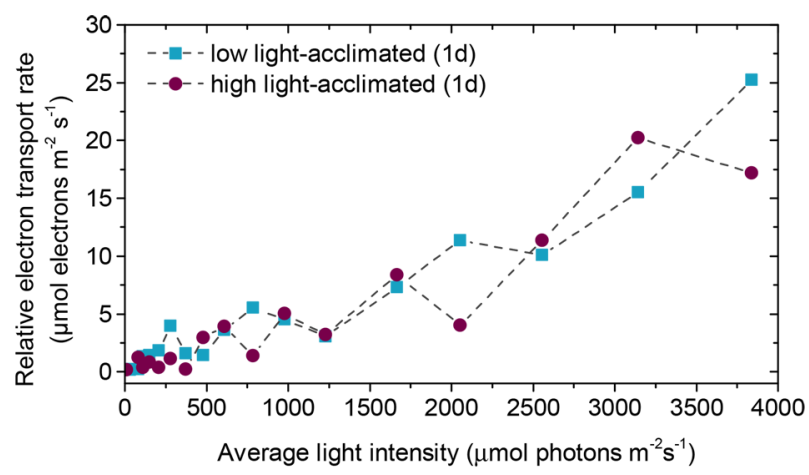

(b) D. parva

Figure 1. Relationship between electron transport rate and average light intensity in D. salina (a) and D. parva (b).

48 special emphasis was placed on the morphological differences, 49 the productivity in terms of biomass and $\beta$-carotene, and the 50 adaptational stress response as well as differences in photo51 acclimation and photoinhibition. For this purpose, an 52 interdisciplinary work flow composed of experiments and 53 mathematical modeling was developed and applied to D. salina 54 and D. parva.

\section{MATERIALS AND METHODS}

56 Strain, Growth Medium, and Precultivation. The strains 57 D. salina and D. parva used in this work were obtained from the 58 Culture Collection of Algae and Protozoa (Windermere, 59 United Kingdom) and identified based on $18 \mathrm{~S}$ rRNA 60 sequencing. The growth of both stock cultures was performed 61 in a rotary shaking incubator (Multitron, Infors AG, Switzer62 land) in $3.5 \% \mathrm{CO}_{2}$ enriched air, at a temperature of $26^{\circ} \mathrm{C}$, with $63100 \mathrm{rpm}$ rotational speed and a light intensity of $30 \mu \mathrm{mol}$ 64 photons $\mathrm{m}^{-2} \mathrm{~s}^{-1}$ applied in alternating day/night cycles $(16 \mathrm{~h} / 8$ $65 \mathrm{~h})$. The growth medium composition was as follows: $1.50 \mathrm{M}$ $66 \mathrm{NaCl}, 22.50 \mathrm{mM} \mathrm{Na} \mathrm{SO}_{4}, 4.87 \mathrm{mM} \mathrm{K}_{2} \mathrm{SO}_{4}, 1.00 \mathrm{mM}$ $67 \mathrm{NaH}_{2} \mathrm{PO}_{4}, 0.37 \mathrm{mM} \mathrm{MgCl}, 19.35 \mathrm{mM} \mathrm{Na} 2$ EDTA, $18.9 \mathrm{mM}$ ${ }_{68} \mathrm{CaCl}_{2}, 11.25 \mathrm{mM}$ NaFe EDTA, $1.89 \mathrm{mM} \mathrm{MnCl}, 1.48 \mathrm{mM}$ $69 \mathrm{ZnSO}_{4}, 0.67 \mathrm{mM} \mathrm{CuSO}, 10.95 \mathrm{nM} \mathrm{Na} \mathrm{MoO}_{4}$, and $9.95 \mathrm{nM}$ $70 \mathrm{CoCl}_{2}$. The nitrogen-replete medium contained $37.75 \mathrm{mM}$ $71 \mathrm{KNO}_{3}$, whereas the nitrogen-depleted medium contained an 72 equimolar content of $\mathrm{KCl}$.

73 Cultivation Experiments in Flat-Plate Photobioreac74 tors. Cultivations were performed in flat-plate photobior75 eactors either with $1 \mathrm{~L}$ cultivation volume (FMT 150, Photon 76 Systems Instruments) equipped with white and red LEDs (for 77 D. parva) or with $1.8 \mathrm{~L}$ cultivation volume (Labfors Lux, Infors $78 \mathrm{HT}$ ) equipped with warm white LEDs (for D. salina). Both 79 reactors were bubbled with a gas mixture of $97 \%$ air and $3 \%$ $80 \mathrm{CO}_{2}$ at $500 \mathrm{~mL} \mathrm{~min}{ }^{-1}$ flow rate provided by mass flow 81 controllers. The $\mathrm{pH}$ was maintained at 7.5 by the addition of 1 $82 \mathrm{M} \mathrm{HCl}$ and $1 \mathrm{M} \mathrm{KOH}$, and the temperature was set to $24{ }^{\circ} \mathrm{C}$. 83 An optical $\mathrm{pO}_{2}$ electrode (Visiferm DO, Hamilton Messtechnik $84 \mathrm{GmbH}$, Switzerland) was used to measure the dissolved oxygen 85 concentration in the reactors. The transmitted light intensity 86 was determined using a light sensor on the backside of the 87 reactor (ULM-500, Walz or Infors HT).

88 Carbon and Nitrogen Fraction in the Biomass. The 89 carbon and nitrogen cell quota of the biomass were determined 90 by $\mathrm{C} / \mathrm{H} / \mathrm{N}$ analysis from freeze-dried samples (Currenta, 91 Germany).
Ion Chromatography. Extracellular nitrogen density was 92 measured by ion chromatography (Dionex ICS 1100, Thermo 93 Scientific Dionex, USA) using an Ion Pak AS22 column 94 (Thermo Scientific Dionex, USA) with $4.5 \mathrm{mM}$ sodium 95 carbonate and $1.4 \mathrm{mM}$ sodium bicarbonate as mobile phase 96 at a flow rate of $1.2 \mathrm{~mL} \mathrm{~min}^{-1}$ and with an injection volume of 97 $50 \mu \mathrm{L}$.

Spectrophotometrical Determination of Chlorophyll 99 and Carotenoid Fractions. UV/vis spectrophotometry was 100 used to measure the carotenoid and chlorophyll fractions in the 101 biomass. Briefly, a 3-10 mL sample was taken from the reactor 102 depending on the cell density and pigment fraction. After the 103 cells were filtered onto glass microfiber filters (GF/F, $0.7 \mu \mathrm{m}, 104$ Whatman, UK), a washing step with $0.5 \mathrm{M}$ ammonium formate, 105 followed by the addition of $6 \mathrm{~mL}$ of $90 \%$ acetone was 106 performed. The pigment extract was incubated for $1 \mathrm{~h}$ at $4{ }^{\circ} \mathrm{C} 107$ in a mixing block at $100 \mathrm{rpm}$. The mixture was centrifuged 5108 $\mathrm{min}$ at $3000 \mathrm{~g}$ to separate the cell debris from the pigment 109 extract. The supernatant was measured with a spectropho- 110 tometer (Specord S600, Analytik Jena, Germany) at 470, 645, 111 and $661.5 \mathrm{~nm}$. The pigment densities of the sample were 112 calculated according the equations given below. ${ }^{4}$

$$
\begin{aligned}
& c_{\text {Chla }}=\left(11.24 A_{661}-2.04 A_{645}\right) \\
& c_{\mathrm{Chlb}}=\left(20.13 A_{645}-4.19 A_{661}\right) \\
& c_{\mathrm{Car}}=\frac{\left(1000 A_{470}-1.9 c_{\mathrm{Chla}}-63.14 c_{\mathrm{Chlb}}\right)}{214}
\end{aligned}
$$

Flow Cytometric Analysis. A flow cytometric measure- 114 ment was conducted to determine the cell density in the reactor 115 using volumetric counting of $200 \mu \mathrm{L}$ culture suspension. 116 Therefore, all samples were diluted to a cell density of 117 approximately $1 \times 10^{6}$ cells $\mathrm{mL}^{-1}$ prior to analysis. Light 118 scattering and fluorescence emission was excited with a blue 119 argon solid state $(488 \mathrm{~nm}$ ) laser in a flow cytometer (CyFlow 120 Space, Sysmex-Partec, Germany). The samples were measured 121 with a flow rate of $1 \mu \mathrm{L} \mathrm{s}^{-1}$ in $1.5 \mathrm{M} \mathrm{NaCl}$ as sheath fluid. $\quad 122$

Pulse Amplitude Modulation (PAM) Fluorometry. The 123 relative electron transport rate (ETR) was measured using the 124 Dual-PAM 100 fluorometer (Walz, Germany) as previously 125 described in Fachet et al. ${ }^{5}$ Briefly, $1.5 \mathrm{~mL}$ of cell sample was 126 dark adapted for $10 \mathrm{~min}$ at $26{ }^{\circ} \mathrm{C}$. Afterward, the minimal 127 fluorescence level $\left(F_{0}\right)$ and maximal fluorescence level $\left(F_{\mathrm{m}}\right) 128$ induced by a saturating actinic light pulse $(635 \mathrm{~nm}, 2000 \mu \mathrm{mol} 129$ photons $\mathrm{m}^{-2} \mathrm{~s}^{-1}, 0.5 \mathrm{~s}$ ) were determined with a measuring 130 radiation of $5 \mu \mathrm{mol} \mathrm{m}^{-2} \mathrm{~s}^{-1}$. Subsequently, the actinic light was 131 
(a)

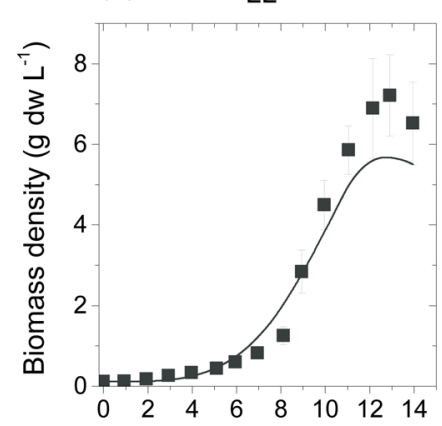

(d)

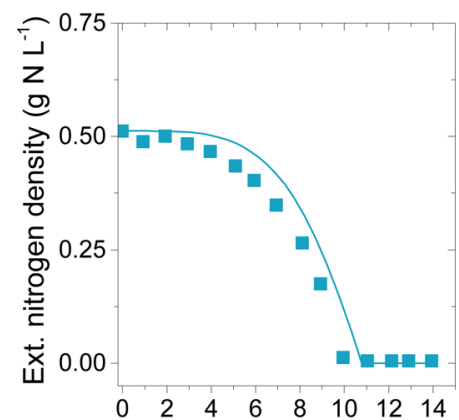

(g)

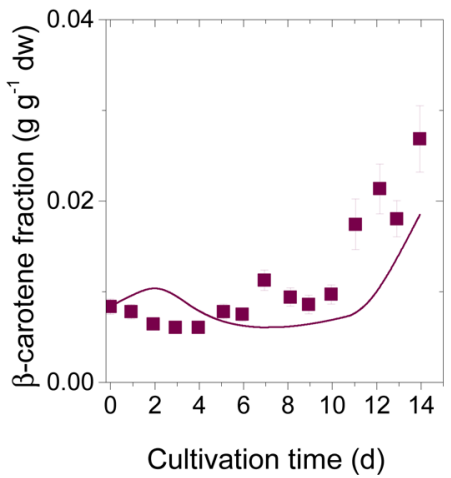

(b)

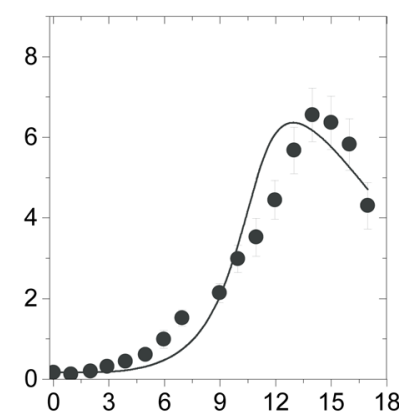

(e)

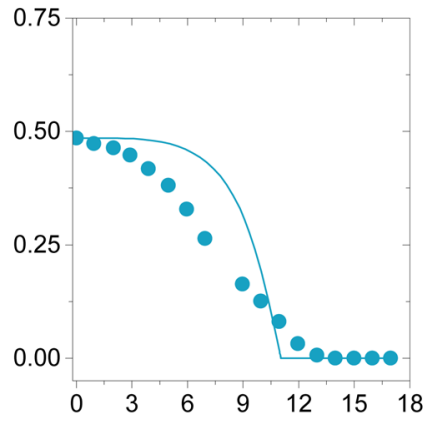

(h)

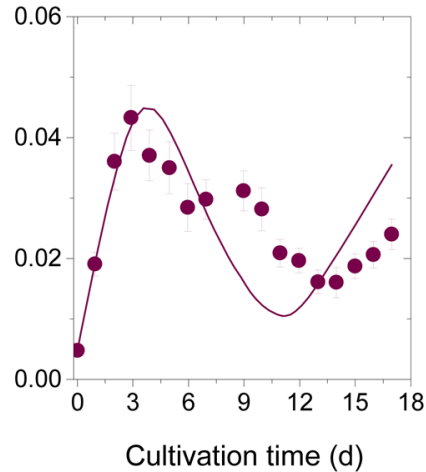

(c) HL-ND

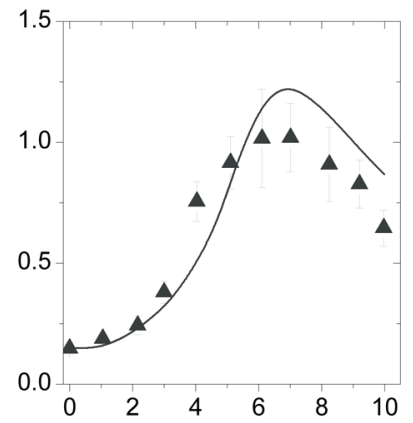

(f)

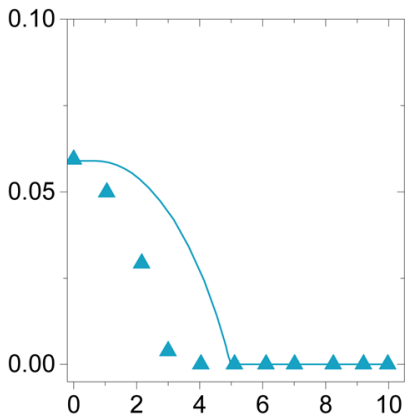

(i)

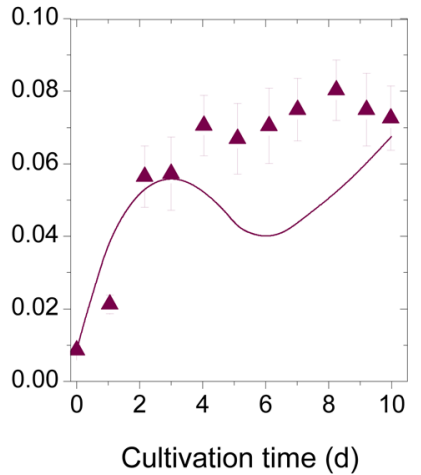

Figure 2. Model simulations for $D$. salina for the effect of various cultivation conditions on the biomass density $\rho_{\mathrm{X}, \mathrm{dw}}(\mathrm{a}-\mathrm{c})$, the extracellular nitrogen density $\rho_{\mathrm{N}, \text { ext }}(\mathrm{d}-\mathrm{f})$ and the $\beta$-carotene fraction $\omega_{\mathrm{Car}}(\mathrm{g}-\mathrm{i})$. Comparison of the simulated time course (lines) with experimental data (symbols). The symbols represent the mean values and the error bars correspond to the standard deviation. An initial biomass density of $0.1 \mathrm{~g} d w \mathrm{~L}^{-1}$ was used for inoculation. The illumination of the reactor was performed as stated in Table S3 in the Supporting Information.

132 turned on to determine the photosynthetic parameters of the 133 light adapted state. After the light-adapted fluorescence signal $134 F^{\prime}$ reached steady-state, a saturation pulse was applied to the 135 culture which induced the closure of all reaction centers and the 136 value for light-adapted maximal fluorescence $F_{\mathrm{m}}^{\prime}$ was achieved.

\section{RESULTS AND DISCUSSION}

138 Strain Identification of D. salina and D. parva. Both 139 strains were ordered from the Culture Collection of Algae and 140 Protozoa (CCAP) and assigned based on morphological 141 properties and $18 \mathrm{~S}$ rRNA sequencing to D. salina (CCAP $14219 / 18$ ) and D. parva (CCAP 19/10). Both strains had a $100 \%$ 143 query coverage (99\% Max. ID) with D. parva and D. salina, 144 respectively.

145 Experimental Analysis of Interspecies Variability. 146 Morphological Variability between D. salina and D. parva. 147 Beside D. salina, D. parva and D. pseudosalina are known to 148 belong to the carotenogenic species of the Dunaliella genus. ${ }^{6}$
Like D. salina, D. parva is a hypersaline alga tolerating $\mathrm{NaCl} 149$ fractions from $3 \%(\mathrm{w} / \mathrm{w}) \mathrm{NaCl}$ to saturation and an optimal 150 salinity range from 6 to $8 \%(\mathrm{w} / \mathrm{w}){ }^{6}$ In contrast to $D$. salina 151 which has a carotenoid content of 8 to $10 \%(\mathrm{w} / \mathrm{w})$, the 152 maximum carotenoid fraction reported for D. parva is about $5 \% \quad 153$ $(\mathrm{w} / \mathrm{w}) .^{6}$

The most distinctive features between $D$. salina and $D$. parva 155 were the cell size and the dry weight. The results of the 156 comparison are shown in Supporting Information Table S1 and 157 showed a high morphological and physiological variability 158 among the studied species. The length of a single D. parva cell 159 was only half the cell length of $D$. salina $(7.6 \mu \mathrm{m}$ compared to 160 $14.6 \mu \mathrm{m})$ and the cell width was only one-third of D. salina (3.8 161 $\mu \mathrm{m}$ compared to $11.6 \mu \mathrm{m}$ ). The significant differences in the 162 cell size also translated into the cellular dry weight. An average 163 D. parva cell had a weight of only $33.5 \mathrm{pg} \mathrm{cell}^{-1}$, whereas the D. 164 salina cell had a weight of $520 \mathrm{pg} \mathrm{cell}^{-1}$ when cultivated under 165 low-light and nutrient-repleted conditions. The size measure- 166 
Table 1. Optimal Parameter Values $\hat{\boldsymbol{\Theta}}$ as Well as the Individual Confidence Intervals $\left[\sigma_{i}^{-} ; \sigma_{i}^{+}\right]$Corresponding to a Confidence Level of $\mathbf{9 5 \%}$ from Constrained Nonlinear Optimization and Profile Likelihood Analysis for D. salina

\begin{tabular}{|c|c|c|c|c|c|}
\hline strain & symbol & $\hat{\Theta}$ & $\sigma_{i}^{-}$ & $\sigma_{i}^{+}$ & identifiability \\
\hline \multirow[t]{9}{*}{$\begin{array}{l}\text { D. } \\
\text { salina }\end{array}$} & $r_{\mathrm{N}, \max }$ & 0.346 & 0.249 & 0.531 & $\begin{array}{l}\text { structurally and } \\
\text { practically identifiable }\end{array}$ \\
\hline & $K_{\mathrm{s}, \mathrm{N}}$ & 0.005 & 0.0003 & 3.591 & $\begin{array}{l}\text { structurally and } \\
\text { practically identifiable }\end{array}$ \\
\hline & $\mu_{\max }$ & 1.708 & 1.406 & 2.130 & $\begin{array}{l}\text { structurally and } \\
\text { practically identifiable }\end{array}$ \\
\hline & $K_{\mathrm{s}, \mathrm{E}}$ & 0.033 & 0.018 & 0.055 & $\begin{array}{l}\text { structurally and } \\
\text { practically identifiable }\end{array}$ \\
\hline & $K_{\mathrm{i}, \mathrm{E}}$ & 68.719 & 48.186 & 97.744 & $\begin{array}{l}\text { structurally and } \\
\text { practically identifiable }\end{array}$ \\
\hline & $E_{\text {car,crit }}$ & 77.718 & 74.102 & 80.138 & $\begin{array}{l}\text { structurally and } \\
\text { practically identifiable }\end{array}$ \\
\hline & $r_{\mathrm{car}, \mathrm{E}}$ & 0.032 & 0.022 & 0.041 & $\begin{array}{l}\text { structurally and } \\
\text { practically identifiable }\end{array}$ \\
\hline & $r_{\mathrm{car}, \mathrm{N}}$ & 0.005 & 0.0045 & 0.0055 & $\begin{array}{l}\text { structurally and } \\
\text { practically identifiable }\end{array}$ \\
\hline & $r_{\mathrm{R}}$ & 0.142 & 0.131 & 0.152 & $\begin{array}{l}\text { structurally and } \\
\text { practically identifiable }\end{array}$ \\
\hline
\end{tabular}

167 ments were in line with the values published by Borowitzka and 168 Siva $^{6}$ and are given in Table S1 for comparison.

169 Biotechnological Parameters for Growth and $\beta$-Carotene 170 Accumulation. Batch cultivations of $D$. salina and $D$. parva 171 were carried out in order to identify interspecies differences in 172 biomass formation and pigment accumulation (see Tables S2 173 and S3 for experimental conditions). The biotechnological 174 parameters listed in Tables S4 and S5 indicated that D. salina 175 outperformed $D$. parva in almost all cases. The highest content 176 of $\beta$-carotene was observed under HL-ND conditions with $1778.0 \%(\mathrm{w} / \mathrm{w})$ for D. salina and $4.9 \%(\mathrm{w} / \mathrm{w})$ for D. parva and is in line with values reported by Borowitzka and Siva. ${ }^{6}$ Although the 178 initial nitrate density of the HL-ND batch of D. parva was lower 179 compared to the HL-ND batch of D. salina (0.017 $\mathrm{g} \mathrm{N} \mathrm{L}^{-1} 180$ compared to $0.05 \mathrm{~g} \mathrm{~N} \mathrm{~L}^{-1}$ ), the incorporation into the biomass 181 seems to be more efficient since the final biomass density for $D .182$ parva was $35 \%$ higher. Indeed, the elemental composition 183 analysis revealed a minimum nitrogen cell quota of $0.02 \mathrm{~g} \mathrm{~N} \mathrm{~g}^{-1} 184$ $\mathrm{dw}$ for $D$. parva whereas $0.03 \mathrm{~g} \mathrm{~N} \mathrm{~g}^{-1} \mathrm{dw}$ was measured for $D .185$ salina (Tables S6 and S7).

Photosynthetic Performance. The relative ETR is an 187 indicator for the photosynthetic capacity of cells and therefore 188 linked to the ability for providing energy for cell growth and 189 metabolism. It is calculated as described in eq 1 by 190 multiplication of the average light intensity $(\bar{E})$ with the 191 effective quantum yield $\left(\Phi_{\text {PSI,eff }}\right)$ and the default ETR factor of 192 0.42. The default ETR factor originates from a "model" leaf 193 and describes the fraction of the incident light intensity in the 194 PAR region that is absorbed in PSII.

$$
\mathrm{ETR}=0.42 \Phi_{\mathrm{PSII}, \mathrm{eff}} \bar{E}=0.42 \frac{F_{\mathrm{m}}^{\prime}-F^{\prime}}{F_{\mathrm{m}}^{\prime}} \bar{E}
$$

The relationship between relative ETR and average light 197 intensity for $D$. salina is shown in Figure 1a. The curve clearly $198 \mathrm{fl}$ shows the three characteristic phases (light limitation, light 199 saturation, and photoinhibition). Under both conditions (low- 200 and high-light acclimated cells), the ETR for D. salina increased 201 linearly until a light intensity of $550 \mu \mathrm{mol}$ photons $\mathrm{m}^{-2} \mathrm{~s}^{-1}$ was 202 reached. In this light regime, the light intensity directly 203 correlates with the rate of photosynthesis. Both cultures of D. 204 salina reached a maximal ETR value of 6.9 to $8.3 \mu \mathrm{mol} 205$ electrons $\mathrm{m}^{-2} \mathrm{~s}^{-1}$ (Figure 1a). The light saturation range for the 206 low light-acclimated culture was from 550-860 $\mu$ mol photons 207

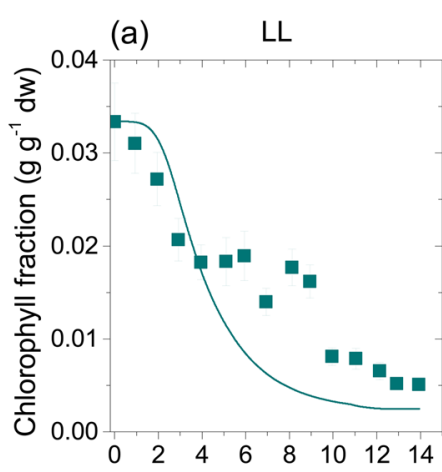

(d)

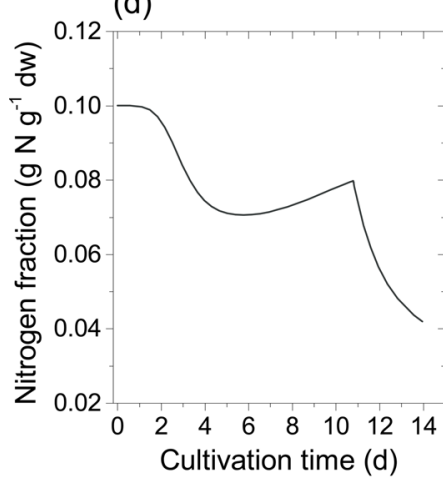

(b)

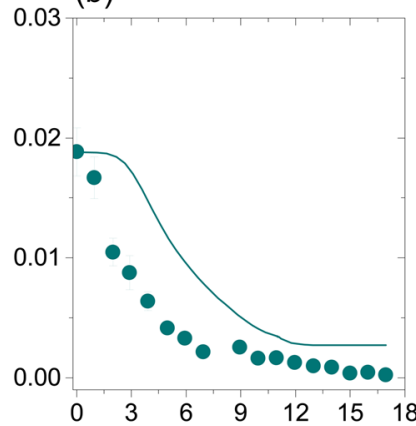

(e)

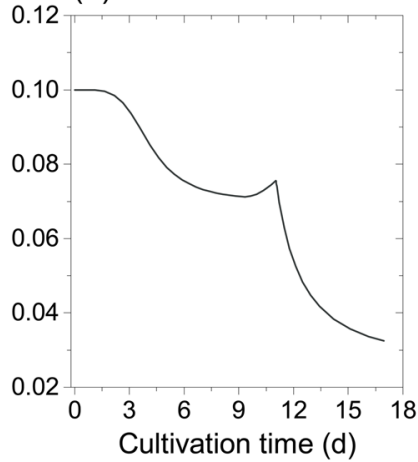

(c) HL-ND
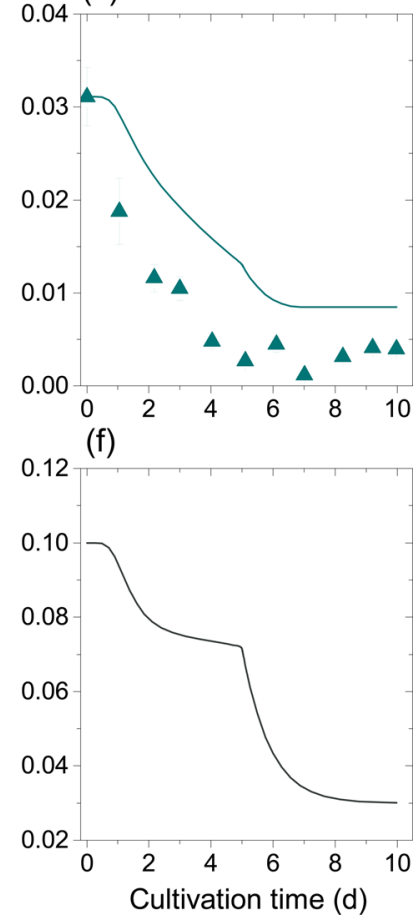

Figure 3. Model simulations for $D$. salina for the effect of various cultivation conditions on the chlorophyll fraction $\omega_{\mathrm{Chl}}(\mathrm{a}-\mathrm{c})$ and the nitrogen quota in the biomass $\omega_{\mathrm{N}}(\mathrm{d}-\mathrm{f})$. Comparison of the simulated time course (lines) with experimental data (symbols). The symbols represent the mean values and the error bars correspond to the standard deviation. 
(a)

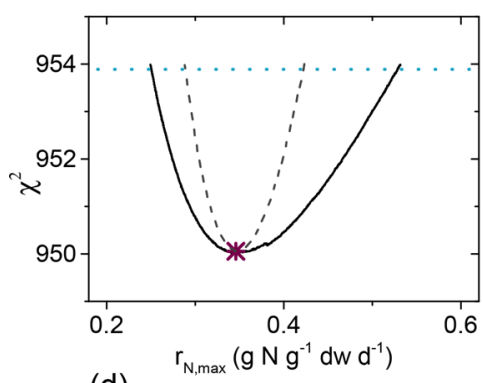

(d)

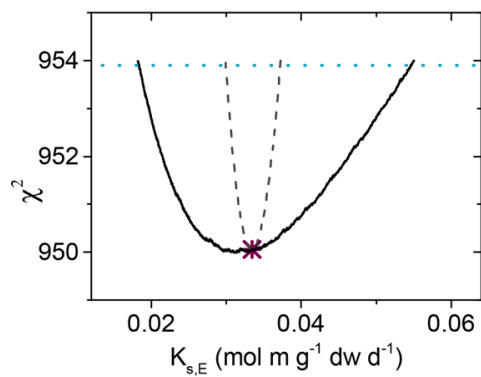

(g)

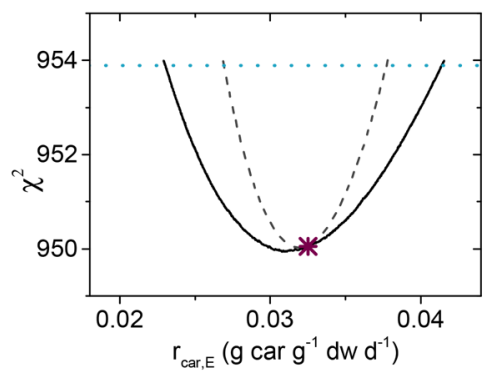

(b)

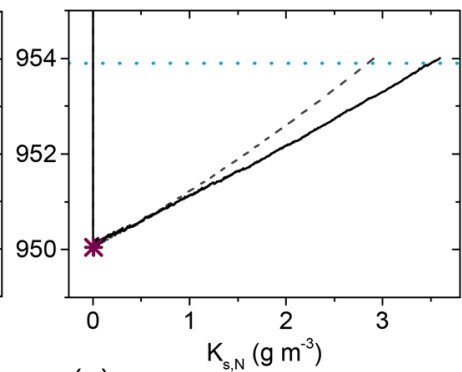

(e)

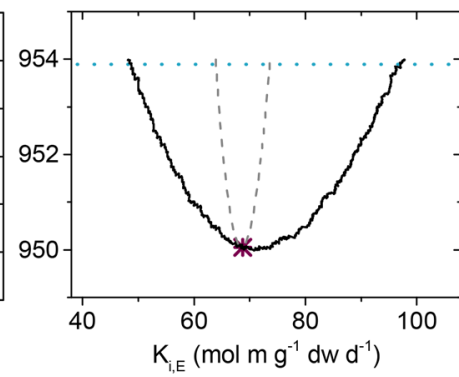

(h)

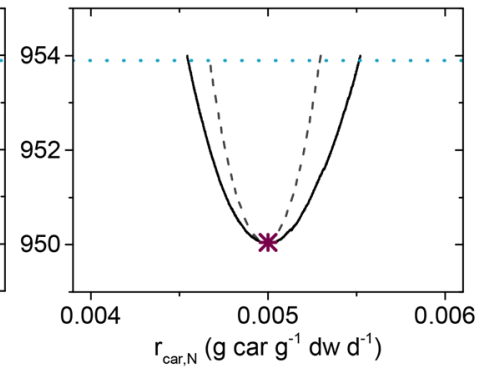

(c)

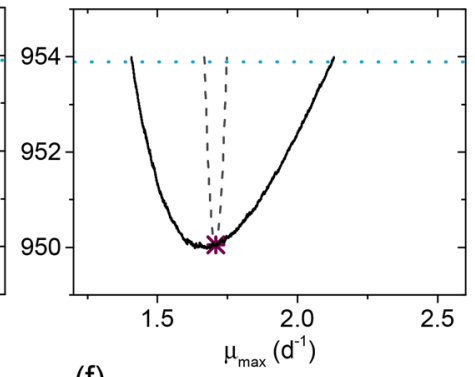

(f)

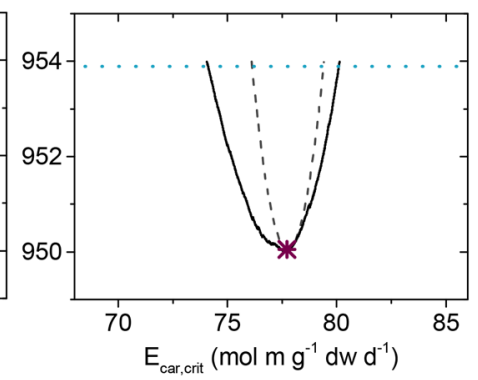

(i)

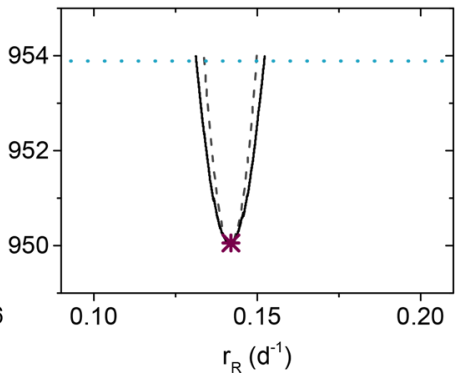

Figure 4. Profile likelihood-based identifiability for all model parameters for D. salina: (a) maximal nitrogen uptake rate $r_{\text {max }}$ (b) half-saturation coefficient for nitrogen uptake $K_{\mathrm{s}, \mathrm{N}},(\mathrm{c})$ maximal growth rate $\mu_{\max }$ (d) half-saturation coefficient for photosynthetic growth $K_{\mathrm{s}, \mathrm{E}}$, (e) light inhibition coefficient for photosynthetic growth $K_{\mathrm{i}, \mathrm{E}},(\mathrm{f})$ critical light intensity for $\beta$-carotene synthesis $E_{\text {car,crit }}(\mathrm{g})$ light stress-induced $\beta$-carotene synthesis rate $r_{\mathrm{car}, \mathrm{E}},(\mathrm{h})$ nutrient stress-induced $\beta$-carotene synthesis rate $r_{\mathrm{car}, \mathrm{N}}$ and (i) respiration rate $r_{\mathrm{R}}$. The profile likelihood-based sensitivity curve, where $\Theta_{\mathrm{i}}$ is varied and all other parameters $\Theta_{j \neq i}$ are kept constant, is indicated by the dashed gray line. The profile likelihood-based identifiability curves are indicated by the black solid line. The blue dotted horizontal line indicates the threshold utilized to assess likelihood-based $95 \%$ confidence interval and the asterisk corresponds to the optimal parameter value.

$208 \mathrm{~m}^{-2} \mathrm{~s}^{-1}$, whereas the high light-acclimated culture showed a 209 prolonged light saturation phase from 550-1070 $\mu$ mol photons $210 \mathrm{~m}^{-2} \mathrm{~s}^{-1}$. The light saturation phase is followed by a 211 photoinhibition phase in which the ETR declined to about 4 $212 \mu \mathrm{mol}$ electrons $\mathrm{m}^{-2} \mathrm{~s}^{-1}$ at $2200 \mu \mathrm{mol}$ photons $\mathrm{m}^{-2} \mathrm{~s}^{-1}$.

213 Beside the differences in morphology and biotechnological 214 parameters, further variability of D. parva compared to D. salina 215 was observed in the response upon exposure to oversaturating 216 light conditions as illustrated in Figure $1 \mathrm{~b}$, where the 217 dependency of the ETR on the average light intensity is 218 given. In contrast to $D$. salina, a pronounced saturation and 219 photoinhibitory phase could not be observed, neither for low 220 light nor for high light-acclimated D. parva cells. Because of the 221 absence of a photoinhibition phase in D. parva, the maximal 222 ETR of $25 \mu \mathrm{mol}$ electrons $\mathrm{m}^{-2} \mathrm{~s}^{-1}$ is three times higher 223 compared to the maximal ETR achieved for D. salina.

224 Dynamic-Kinetic Growth Model for $D$. salina and $D$. 225 parva. In the following section, the interspecies variability 226 between $D$. salina and $D$. parva was analyzed with a model227 based approach, namely a dynamic-kinetic growth model. The 228 experimental data for the simulations were obtained as specified 229 in Tables S2 and S3.
Model Formulation. The presented dynamic-kinetic 230 growth model is based on an ordinary differential equation 231 (ODE) system published by Fachet et al. ${ }^{8}$ with the extension to 232 account for photoacclimation, photoinhibition, and $\beta$-carotene 233 accumulation (see eqs 2 and 3 ). The following five state 234 variables were considered:

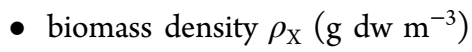

- extracellular nitrogen density $\rho_{\mathrm{N}}\left(\mathrm{g} \mathrm{N} \mathrm{m}^{-3}\right)$

- intracellular nitrogen fraction $\omega_{\mathrm{N}}\left(\mathrm{g} \mathrm{N} \mathrm{g}^{-1} \mathrm{dw}\right)$

- chlorophyll fraction $\omega_{\mathrm{Chl}}\left(\mathrm{g} \mathrm{Chl} \mathrm{g}{ }^{-1} \mathrm{dw}\right)$

- $\beta$-carotene fraction $\omega_{\mathrm{Car}}\left(\mathrm{g}\right.$ Car $\left.\mathrm{g}^{-1} \mathrm{dw}\right)$

The complete algebraic equation system can be found in the 241 Supporting Information.

242

$\beta$-Carotene Synthesis Rate. The synthesis of $\beta$-carotene 243 mainly depends on the presence and intensity of light and 244 nutrient stress. Therefore, the equation for its synthesis couples 245 a light-dependent and nutrient-dependent synthesis term as 246 formulated below (eq 2): 
(a)

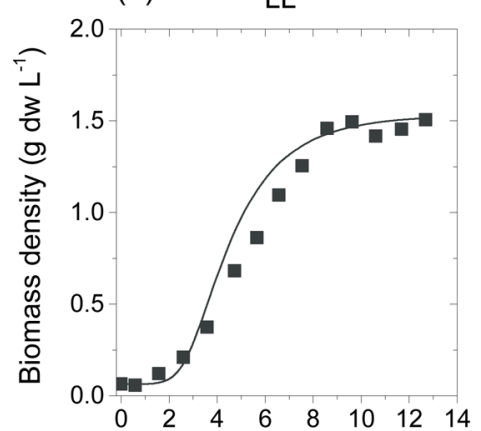

(d)

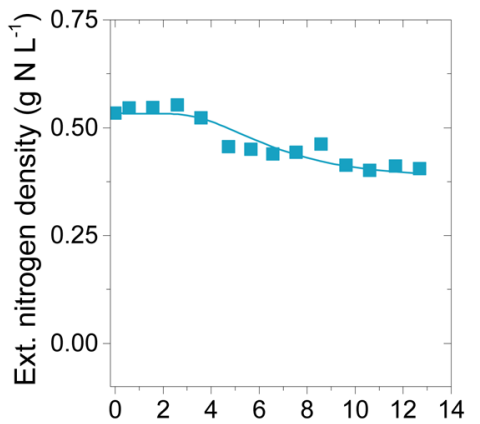

(g)

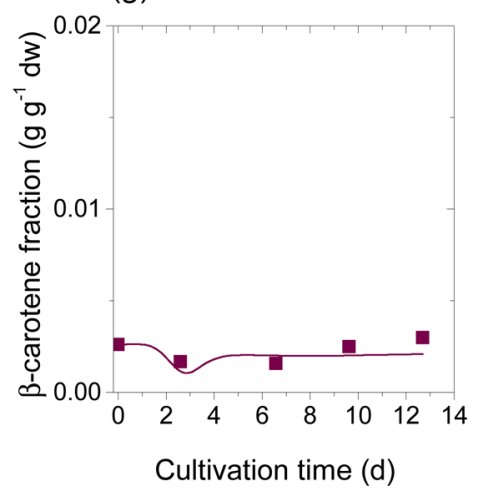

(b)

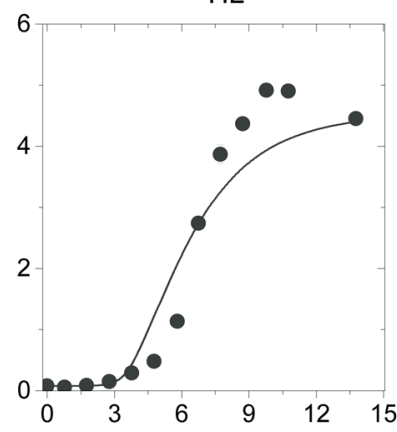

(e)

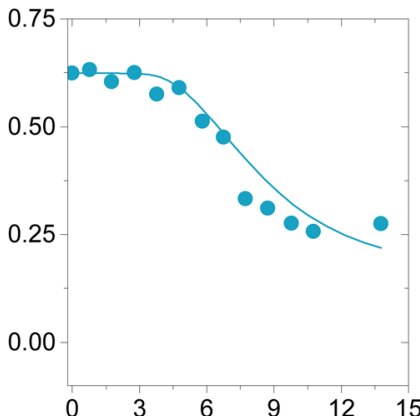

(h)

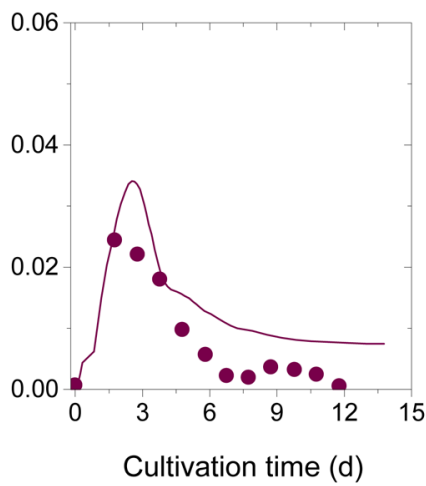

(c)

HL-ND

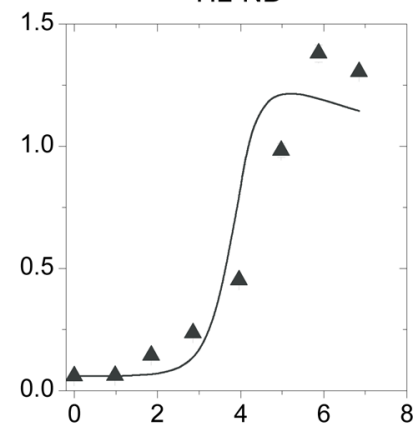

(f)

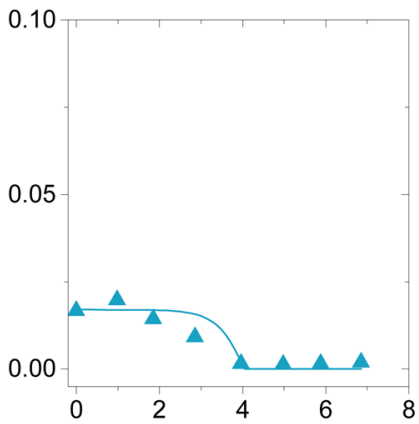

(i)

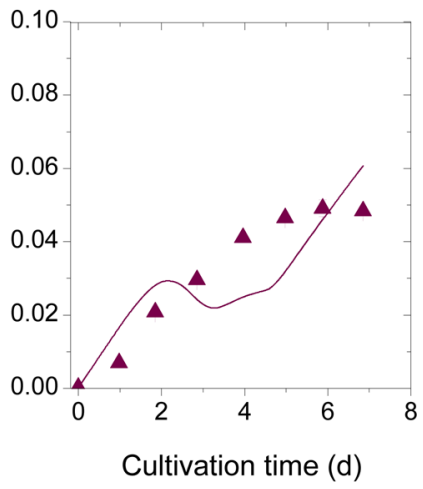

Figure 5. Model simulations for D. parva for the effect of various cultivation conditions on the biomass density $\rho_{\mathrm{X}}(\mathrm{a}-\mathrm{c})$, the extracellular nitrogen density $\rho_{\mathrm{N}, \text { ext }}(\mathrm{d}-\mathrm{f})$, and the $\beta$-carotene fraction $\omega_{\mathrm{Car}}(\mathrm{g}-\mathrm{i})$. Comparison of the simulated time course (lines) with experimental data (symbols). The symbols represent the mean values and the error bars correspond to the standard deviation. An initial biomass density of $0.1 \mathrm{~g} d w \mathrm{~L}^{-1}$ was used for inoculation. The illumination of the reactor was performed as stated in Table S4 in the Supporting Information.

$$
r_{\mathrm{Car}}=r_{\mathrm{Car}, \mathrm{E}} \frac{E_{\mathrm{X}, \mathrm{dw}}^{k}}{E_{\mathrm{car}, \mathrm{crit}}^{k}+E_{\mathrm{X}, \mathrm{dw}}^{k}}+r_{\mathrm{Car}, \mathrm{N}}\left(1-\frac{\omega_{\mathrm{N}}^{k}}{\omega_{\mathrm{N}, \mathrm{crit}}^{k}+\omega_{\mathrm{N}}^{k}}\right)
$$

249 where $r_{\mathrm{Car}, \mathrm{E}}$ and $r_{\mathrm{Car}, \mathrm{N}}$ represent the maximal synthesis rate 250 under light and nutrient stress. The half saturation coefficients 251 for light and nutrient stress are denoted as $E_{\text {car,crit }}$ and $\omega_{\mathrm{N}, \text { crit }}$. 252 The Hill coefficient is represented by $k$ and $E_{\mathrm{X}, \mathrm{dw}}$ is the light 253 intensity per biomass. Please note that the cultivations for $D$. 254 parva were conducted under constant light conditions and the 255 average photon flux density $\bar{E}$ can be used instead of $E_{\mathrm{X}, \mathrm{dw}}$. 256 Growth rate. Since pronounced photoinhibitory effects were 257 observed for growth of $D$. salina under high light conditions, a 258 growth rate approach containing an inhibition term has been 259 formulated to describe the specific biomass growth rate $\mu .^{9}$ In 260 addition, a Droop term has been added to the equation to 261 ensure growth arrest under nitrogen depletion as shown in eq $2623:^{10}$

$$
\mu=\mu_{\max } \frac{E_{\mathrm{X}, \mathrm{dw}}}{E_{\mathrm{X}, \mathrm{dw}}+K_{\mathrm{S}, \mathrm{E}} \frac{\rho_{\mathrm{X}}}{\rho_{\mathrm{Chl}}}+\frac{E_{\mathrm{X}, \mathrm{dw}}^{2}}{K_{\mathrm{i}, \mathrm{E}}}}\left(1-\frac{\omega_{\mathrm{N}, \min }}{\omega_{\mathrm{N}}}\right)
$$

The following five dynamic equations are deduced from the 264 algebraic equations in order to describe biomass growth, 265 chlorophyll, and $\beta$-carotene fraction, extracellular nitrogen 266 density and nitrogen quota:

$$
\begin{aligned}
& \frac{\mathrm{d} \rho_{\mathrm{X}}}{\mathrm{d} t}=\mu_{\mathrm{net}} \rho_{\mathrm{X}} \\
& \frac{\mathrm{d} \rho_{\mathrm{N}, \text { ext }}}{\mathrm{d} t}=-r_{\mathrm{N}} \rho_{\mathrm{X}} \\
& \frac{\mathrm{d} \omega_{\mathrm{N}}}{\mathrm{d} t}=r_{\mathrm{N}}-\mu \omega_{\mathrm{N}}
\end{aligned}
$$


(a) LL

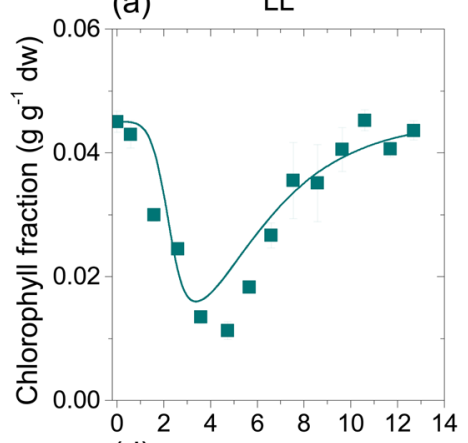

(d)

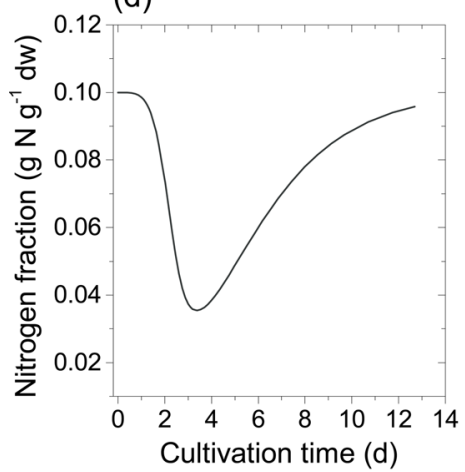

(b)

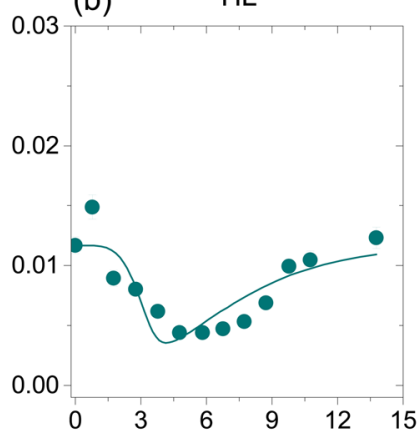

(e)

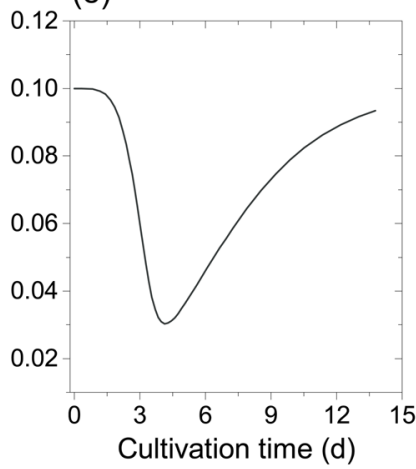

(c) HL-ND

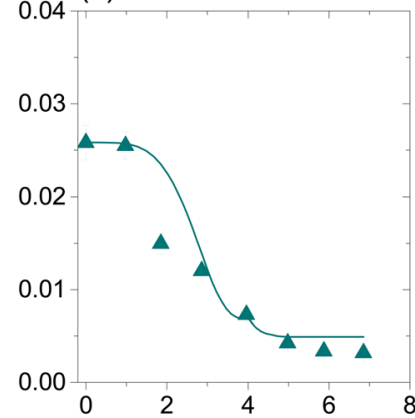

(f)

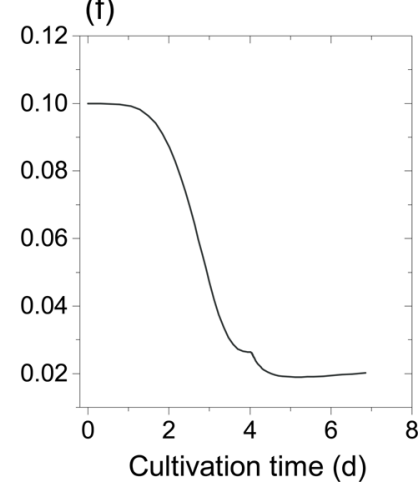

Figure 6. Model simulations for $D$. parva for the effect of various cultivation conditions on the chlorophyll fraction $\omega_{\mathrm{Chl}}(\mathrm{a}-\mathrm{c})$ and the nitrogen quota in the biomass $\omega_{\mathrm{N}}(\mathrm{d}-\mathrm{f})$. Comparison of the simulated time course (lines) with experimental data (symbols). The symbols represent the mean values and the error bars correspond to the standard deviation.

271

$$
\frac{\mathrm{d} \omega_{\mathrm{Chl}}}{\mathrm{d} t}=\frac{\omega_{\mathrm{Chl}, \mathrm{N}} \cdot \mu \cdot r_{\mathrm{N}}}{r_{\mathrm{P}} \cdot\left(\frac{\omega_{\mathrm{Chl}}}{\omega_{\mathrm{C}}}\right)}-\mu_{\mathrm{net}} \omega_{\mathrm{Chl}}
$$

$272 \quad \frac{\mathrm{d} \omega_{\mathrm{Car}}}{\mathrm{d} t}=r_{\mathrm{Car}}-\mu_{\text {net }} \omega_{\mathrm{Car}}$

273 The model equations contain 9 parameters (optimization 274 variables) and 11 biomass and three reactor constants (see 275 Tables S6 and S7).

276 The proposed model was implemented in MATLAB 277 (MathWorks) and solved by using CVODES. ${ }^{11}$ The model 278 simulations were compared with the experimental data of $D$. 279 salina and $D$. parva grown under different cultivations 280 conditions (Tables S2 and S3) in flat-plate photobioreactors 281 in batch mode. The parameter estimation was performed using 282 the nonlinear optimization algorithm fmincon with an initial 283 parameter set based on literature and experimental data. This 284 algorithm minimizes the objective function as defined in eq 9:

285

$$
\chi^{2}(\Theta)=\sum_{k=1}^{m} \sum_{i=1}^{d_{\mathrm{k}}} \frac{1}{\sigma_{\mathrm{ki}}^{2}}\left(y_{\mathrm{k}}\left(t_{\mathrm{i}}\right)-y_{\mathrm{k}}\left(t_{\mathrm{i}}, \Theta\right)\right)^{2}
$$

286 where $m$ is the number of measured outputs, $d_{k}$ is the number 287 of measurement times, $y_{k}$ and $\hat{y}_{k}$ are the $k$ th measured output 288 variable and corresponding model prediction and $\sigma_{\mathrm{ki}}^{2}$ is the 289 variance in the measured data.

290 Parameter Estimation. The nine model parameters of the 291 proposed equation system were estimated to describe the 292 dynamic changes in the biomass density, the chlorophyll, and $\beta$ 293 carotene fraction as well as the extracellular nitrogen density in 294 largest agreement to the experimental data. For this purpose, 295 the objective function was defined to minimize the weighted 296 sum of squared residuals (eq 9$)$ for $\rho_{\mathrm{X}}, \omega_{\mathrm{Chl}}, \omega_{\mathrm{Car}}$, and $\rho_{\mathrm{N}, \mathrm{ext}}$ for three experimental conditions (see LL, HL, and HL-ND in 297 Tables S2 and S3). According to the measurement, results for 298 the biomass-specific parameters of D. salina and D. parva were 299 set as shown in Tables S6 and S7. Box constraints were 300 imposed on the parameters according to biophysical limitations. 301 The measurement variances were parametrized as $\sigma_{k i}^{2}=0.1302$ $\max \left(y_{k}(t)\right)$.

303

Profile Likelihood Analysis of Model Parameters. The 304 reliability and identifiability of the estimated parameter set was 305 studied using profile likelihood analysis. The approach was 306 proposed by Raue et al. ${ }^{12}$ and is based on constrained 307 likelihood profiles. The systematic exploration of the high- 308 dimensional parameter space is done individually for each 309 parameter $\left(\Theta_{i}\right)$ with respect to all other parameters $\Theta_{j \neq i}$ as 310 shown in eq $10 .^{13}$

$$
\chi_{\mathrm{PL}}^{2}\left(\Theta_{\mathrm{i}}\right)=\min _{\Theta_{\mathrm{j} \neq \mathrm{i}}}\left[\chi^{2}(\Theta)\right]
$$

On the basis of the shape of $\chi_{\mathrm{PL}}^{2}\left(\Theta_{\mathrm{i}}\right)$, one can distinguish 313 between structural and practical identifiability or nonidentifi- 314 ability. Structural and practical identifiable parameters have a 315 parabolically shaped $\chi_{\mathrm{PL}}^{2}\left(\Theta_{\mathrm{i}}\right)$ curve and nonidentifiable 316 parameters have a $\chi_{\mathrm{PL}}^{2}$ curve with a flat shape. If the flat 317 shape occurs in the direction of one confidence bound, the 318 parameters are practical nonidentifiable, whereas in the 319 direction of both confidence bounds structural nonidentifi- 320 ability occurs. The profile likelihood algorithm was imple- 321 mented in MATLAB. Absolute and relative tolerances have 322 been set to $10^{-7}$ and $10^{-6}$, respectively.

Results for D. salina. Biomass Growth under Fluctuating 324 Light and Nutrient Conditions. The simulation results shown 325 in Figure $2 \mathrm{a}-\mathrm{c}$ demonstrate that the model describes the $326 \mathrm{f} 2$ dynamics of biomass growth under various light and nutritional 327 conditions with the estimated parameter set $\hat{\Theta}$ (Table 1 ) in a $328 \mathrm{t} 1$ 
(a)

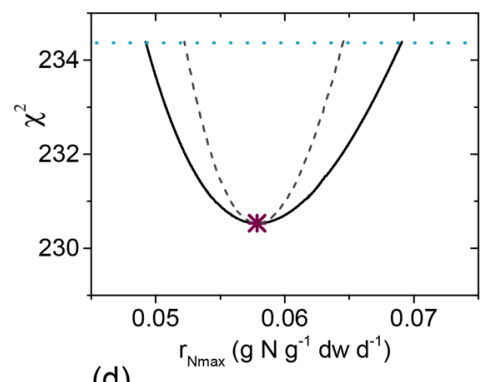

(d)

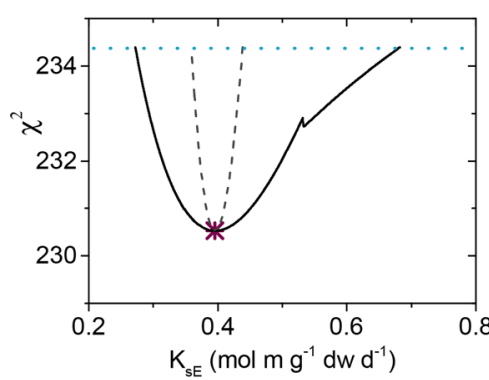

(g)

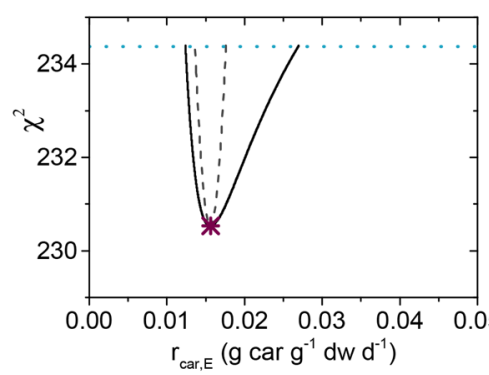

(b)

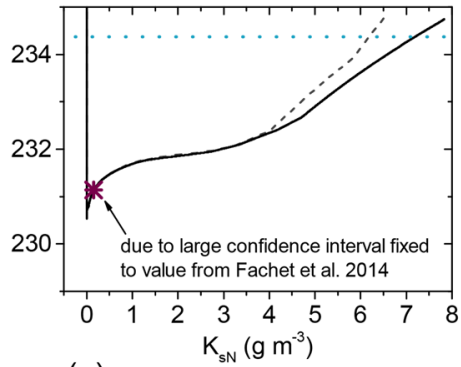

(e)

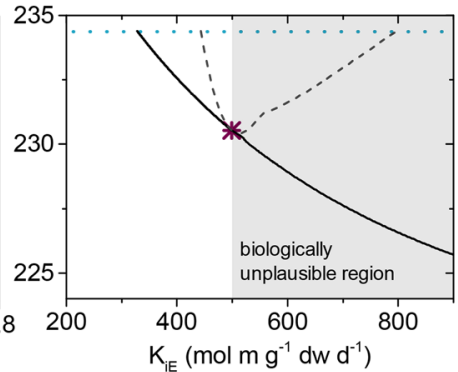

(h)

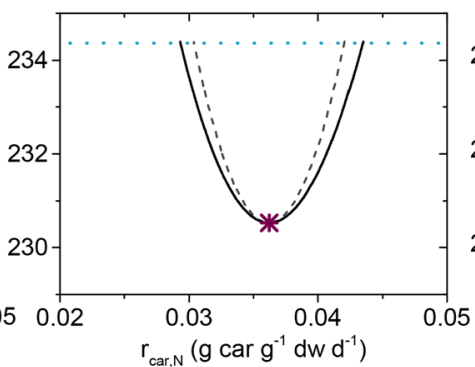

(c)

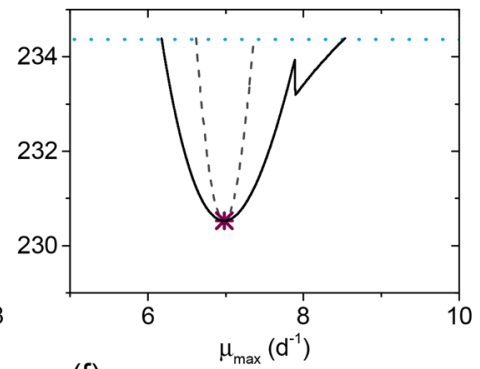

(f)

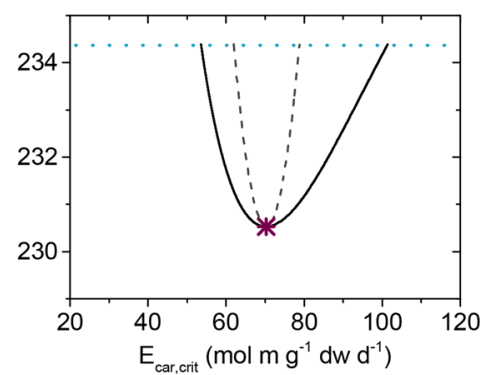

(i)

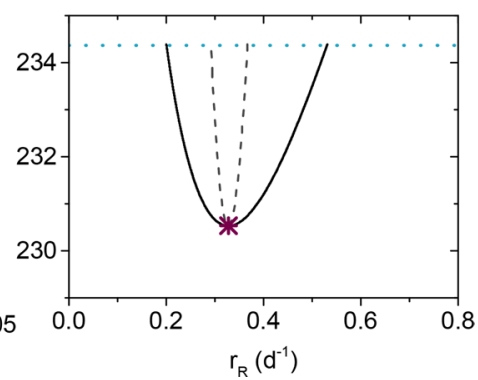

Figure 7. Profile likelihood-based identifiability for all model parameters for $D$. parva: (a) maximal nitrogen uptake rate $r_{\max }$ (b) half-saturation coefficient for nitrogen uptake $K_{\mathrm{s}, \mathrm{N}},(\mathrm{c})$ maximal growth rate $\mu_{\max }$ (d) half-saturation coefficient for photosynthetic growth $K_{\mathrm{s}, \mathrm{E}}$, (e) light inhibition coefficient for photosynthetic growth $K_{\mathrm{i}, \mathrm{E}},(\mathrm{f})$ critical light intensity for $\beta$-carotene synthesis $E_{\mathrm{car}, \text { crit }}(\mathrm{g})$ light stress-induced $\beta$-carotene synthesis rate $r_{\mathrm{car}, \mathrm{E}},(\mathrm{h})$ nutrient stress-induced $\beta$-carotene synthesis rate $r_{\mathrm{car}, \mathrm{N}}$ and (i) respiration rate, $r_{\mathrm{R}}$. The profile likelihood-based sensitivity curve, where $\Theta_{\mathrm{i}}$ is varied and all other parameters $\Theta_{j \neq i}$ are kept constant, is indicated by the dashed gray line. The profile likelihood-based identifiability curves are indicated by the black solid line. The blue dotted horizontal line indicates the threshold utilized to assess likelihood-based $95 \%$ confidence interval and the asterisk corresponds to the optimal parameter value.

Table 2. Optimal Parameter Values $\hat{\boldsymbol{\Theta}}$ as Well as the Individual Confidence Intervals $\left[\sigma_{\mathrm{i}}^{-} ; \sigma_{\mathrm{i}}^{+}\right]$Corresponding to a Confidence Level of $\mathbf{9 5 \%}$ from Constrained Nonlinear Optimization and Profile Likelihood Analysis for D. parva in Comparison with $D$. salina

\begin{tabular}{|c|c|c|c|c|c|c|}
\hline strain & symbol & $\hat{\Theta}$ for $D$. salina & $\hat{\Theta}$ for D. parva & $\sigma_{i}^{-}$ & $\sigma_{i}^{+}$ & identifiability \\
\hline \multirow[t]{9}{*}{ D. parva } & $r_{\mathrm{N}, \max }$ & 0.346 & 0.058 & 0.049 & 0.069 & structurally and practically identifiable \\
\hline & $K_{\mathrm{s}, \mathrm{N}}$ & 0.05 & 0.155 & 0 & 7.832 & structurally and practically identifiable \\
\hline & $\mu_{\max }$ & 1.708 & 6.980 & 6.176 & 8.533 & structurally and practically identifiable \\
\hline & $K_{\mathrm{s}, \mathrm{E}}$ & 0.033 & 0.396 & 0.272 & 0.682 & structurally and practically identifiable \\
\hline & $K_{\mathrm{i}, \mathrm{E}}$ & 68.7190 & 499 & 328.078 & $+\infty$ & practical nonidentifiable, biologically plausible \\
\hline & $E_{\mathrm{car}, \mathrm{crit}}$ & 77.718 & 70.202 & 53.564 & 101.429 & structurally and practically identifiable \\
\hline & $r_{\mathrm{car}, \mathrm{E}}$ & 0.032 & 0.016 & 0.012 & 0.026 & structurally and practically identifiable \\
\hline & $r_{\mathrm{car}, \mathrm{N}}$ & 0.005 & 0.036 & 0.029 & 0.043 & structurally and practically identifiable \\
\hline & $r_{\mathrm{R}}$ & 0.142 & 0.327 & 0.200 & 0.531 & structurally and practically identifiable \\
\hline
\end{tabular}

329 good manner. The maximum biomass density from all three 330 experimental conditions was achieved in the cultivation under 331 low light (LL), namely $7.2 \mathrm{~g} \mathrm{dw} \mathrm{L}^{-1}$. This corresponds to a final 332 cell density of $1.4 \times 10^{7}$ cells $\mathrm{mL}^{-1}$ cultivation volume. The 333 final biomass density reached in the stationary phase for the 334 cultivations under high light (HL) is $6.5 \mathrm{~g} \mathrm{dw} \mathrm{L}^{-1}$ and almost 335 comparable to the low light condition (LL). Under high light 336 and nitrogen depletion (HL-ND) the biomass growth was significantly lowered due to nutrient abundance and only $1.1 \mathrm{~g} 337$ dw $\mathrm{L}^{-1}$ biomass was achieved.

Extracellular Nitrogen Uptake. The simulated time course 339 for the extracellular nitrogen density agreed well with the 340 experimental data (Figure $2 \mathrm{~d}-\mathrm{f}$ ). The results revealed that the 341 growth under all three conditions was always nutrient and 342 never light-limited. As expected, the growth under nutrient- 343 depleted conditions (HL-ND) was governed by the lowest 344 
345 external nutrient availability and the internal nutrient status of 346 the cells. The external nitrogen was totally depleted 4 days after 347 inoculation in the nitrogen starved culture (HL-ND). The 348 simulation results clearly indicate that nitrogen uptake is 349 strongly reduced in the lag phase under nitrogen-repleted 350 conditions (LL, HL), since the nitrogen cell quota is close to its 351 maximal value $\omega_{\mathrm{N}, \max }$ (Figure $2 \mathrm{~d}-\mathrm{f}$ ).

352 The predicted maximal nitrogen uptake rate is $0.346 \mathrm{~g} \mathrm{~N} \mathrm{~g}^{-1}$ $353 \mathrm{dw} \mathrm{d} \mathrm{d}^{-1}$. The value for the calculated nitrogen uptake rate $r_{\mathrm{N}}$, 354 under all three conditions is approximately $0.05 \mathrm{~g} \mathrm{~N} \mathrm{~g}^{-1} \mathrm{dw} \mathrm{d}^{-1}$, 355 which is in good agreement with measurements ranging from $3560.05-0.015 \mathrm{~g} \mathrm{~N} \mathrm{~g} \mathrm{~g}^{-1} \mathrm{dw} \mathrm{d}^{-1}$ measured for several green 357 microalgal species by Hein et al. ${ }^{14}$ However, it is lower than 358 measured nitrogen uptake rates for the same strain used in this 359 study, namely D. salina CCAP $19 / 18$, grown in a low light 360 turbidostat culture $\left(0.085 \mathrm{~g} \mathrm{~N} \mathrm{~g}^{-1} \mathrm{dw} \mathrm{d}^{-1}\right)$ measured by Lamers 361 et al. ${ }^{15}$ and $0.08 \mathrm{~g} \mathrm{~N} \mathrm{~g}^{-1} \mathrm{dw} \mathrm{d}^{-1}$ from Lomas and Glibert ${ }^{16}$ 362 measured for the closely related organism $D$. tertiolecta.

$363 \beta$-Carotene Fraction in the Biomass. The model simu364 lations agree well with the experimental data for the $\beta$-carotene 365 fraction $\omega_{\text {Car }}$ in the cells (Figure $2 \mathrm{~g}-\mathrm{i}$ ). The data clearly 366 indicate that light and nutrient stress alone are able to induce 367 the accumulation of the photoprotective pigments. However, 368 when both stress conditions are combined under HL-ND 369 conditions the $\beta$-carotene synthesis exceeds the fractions 370 achieved under LL or HL conditions. The highest $\beta$-carotene 371 fraction was detected in the HL-ND culture with $8.0 \%(\mathrm{w} / \mathrm{w})$, 372 followed by the HL culture with $4.3 \%(\mathrm{w} / \mathrm{w})$ at day 3 and $2.7 \%$ $373(\mathrm{w} / \mathrm{w})$ in the stationary culture under LL conditions. Under HL 374 conditions the initially high $\beta$-carotene accumulation induced 375 by the presence of light stress declined as soon as the incident 376 light intensity fell below the fixed light stress of $3000 \mu \mathrm{mol} \mathrm{m}{ }^{-2}$ $377 \mathrm{~s}^{-1} \mathrm{~g}^{-1} \mathrm{dw} \mathrm{L}$ due to the physical limitation of the LED light 378 panel to a maximal light intensity of $3000 \mu \mathrm{mol} \mathrm{m}{ }^{-2} \mathrm{~s}^{-1}$. Under $379 \mathrm{LL}$ conditions, the $\beta$-carotene synthesis started when a critical 380 nitrogen quota of approximately $0.075 \mathrm{~g} \mathrm{~N} \mathrm{~g}^{-1} \mathrm{dw}$ was reached. 381 Total Chlorophyll Fraction in the Biomass. The model 382 simulations agree reasonably well with the experimental data for 383 the chlorophyll fraction $\omega_{\mathrm{Ch}}$, which is crucial for predicting the 384 light attenuation in the reactor (Figure $3 a-c$ ). During the initial 385 cultivation period more light energy is supplied per cell than is 386 required for growth, resulting in a considerable decline of the 387 total chlorophyll fraction under all three conditions. The 388 minimal total chlorophyll content in the biomass is almost 389 comparable under three cultivation conditions, namely $0.004 \mathrm{~g}$ $390 \mathrm{Chl} \mathrm{g}^{-1} \mathrm{dw}$.

391 Identifiability Analysis Using the Profile Likelihood. The 392 results of the identifiability analysis of all model parameters 393 using likelihood profiles are presented in Figure 4. This 394 approach allows distinguishing between structural nonidentifi395 able, practical nonidentifiable, and identifiable parameters 396 depending on the shape of $\chi_{\mathrm{PL}}^{2}$ as discussed in Fachet et al. ${ }^{8}$ 397 The lower and upper bounds of the $95 \%$ confidence intervals 398 are given in Table 1 . All nine model parameters are identifiable 399 indicated by the shape of the $\chi_{\mathrm{PL}}^{2}$ curve and the finite size of the 400 derived confidence intervals (Figure $4 a-i$, black solid line, and 401 Table 1). Besides profile likelihood, likelihood analysis is 402 frequently performed to evaluate the predictive power of a 403 proposed model. In contrast to the profile likelihood, where 404 one parameter $\Theta_{i}$ is varied and all other parameters $\Theta_{j \neq i}$ are 405 reoptimized, for conventional likelihood analysis only the 406 parameter value for $\Theta_{i}$ is changed and the remaining parameters $407 \Theta_{j \neq i}$ are kept constant. Because of this, the parameter identifiability analysis using the likelihood function is less strict 408 than the profile likelihood-based identifiability analysis. This is 409 illustrated in Figure 4 (gray dashed lines vs black solid lines). 410 Still, likelihood analysis is useful to identify potentially 411 nonidentifiable parameters.

412

The likelihood of the nine identifiable model parameters 413 seems to be in an asymptotic setting indicated by the parabolic 414 shape with finite size of the $95 \%$ confidence interval (Figure 415 $4 a-i)$. Because of the negligence of the parameter interde- 416 pendencies, the confidence interval derived for each parameter 417 are significantly smaller for the likelihood-based derivation 418 compared to the profile likelihood. This example illustrates the 419 strength of the identifiability analysis based on profile 420 likelihoods leading to detailed information about parameter 421 interdependencies and reliable confidence intervals. The 422 application of optimal experimental design (OED) approaches 423 could be beneficial in order to determine the measurement 424 signal with the highest information content. ${ }^{17,18}$

Results for D. parva. Biomass Growth under Fluctuating 426 Light and Nutrient Conditions. Similar to the results for D. 427 salina, the simulation results for D. parva are in good agreement 428 with the experimental data (Figures 5 and 6). The observed $429 \mathrm{f5f6}$ growth behavior under HL conditions confirmed the result of 430 the PAM analysis that D. parva showed no pronounced 431 photoinhibitory effects (Figure 1b). The highest biomass 432 density on dry weight basis was reached under HL conditions, 433 namely $4.9 \mathrm{~g} \mathrm{dw} \mathrm{L}^{-1}$. The final biomass densities in the 434 stationary phases of the LL and HL-ND conditions are almost 435

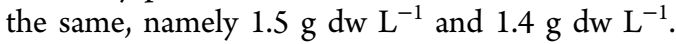

436

Extracellular Nitrogen Uptake. The dynamics in the 437 extracellular nitrogen uptake agree well with the experimental 438 data (Figure 5). The results indicate that the growth under LL 439 and HL conditions (nutrient repletion) was always limited by 440 the availability of light. The growth under nutrient-depleted 441 conditions (HL-ND) was governed by the extracellular 442 nitrogen density, where a complete depletion occurred 4 days 443 after inoculation. The dynamics of the intracellular nitrogen 444 quota $\omega_{\mathrm{N}}$ clearly show that nitrogen uptake is down-regulated 445 in the early exponential and late stationary growth phase under 446 nitrogen repletion (LL and HL conditions), since $\omega_{\mathrm{N}}$ is close to 447 the maximal quota $\omega_{\mathrm{N}, \max }$.

$\beta$-Carotene Fraction in the Biomass. The light and nutrient 449 dependency on the $\beta$-carotene synthesis works in the same way 450 for $D$. parva as observed for D. salina (eq 2). The highest $\beta-451$ carotene fraction was achieved during a combination of light 452 stress and nutrient stress. However, the maximal mass fraction 453 for D. parva is $4.9 \%(\mathrm{w} / \mathrm{w})$ significantly lower compared to that 454 of $D$. salina being $8.0 \%(\mathrm{w} / \mathrm{w})$.

455

Total Chlorophyll Fraction in the Biomass. For the total 456 chlorophyll content in the biomass $\omega_{\mathrm{Chl}}$, a good agreement 457 between simulation results and experimental data is observed 458 (Figure 6). Exactly as detected for D. salina, D. parva shows a 459 considerable degradation of chlorophyll in the initial cultivation 460 period. This is caused by an imbalance in photon supply 461 compared to the photons required for growth. The extent of 462 the chlorophyll degradation strongly depends on the average 463 light intensity in the reactor. For cells cultivated under nitrogen 464 repletion (LL and HL conditions), an accumulation of 465 chlorophyll is observed in the exponential phase to increase 466 the light harvesting efficiency under light limiting conditions. 467 This behavior of chlorophyll synthesis under light limiting 468 conditions has only been observed for D. parva and not for D. 469 salina (see Figure 3). Since growth and chlorophyll synthesis 470 
471 are strongly impaired during nitrogen starvation, the chlor472 ophyll content in the biomass steadily decreases from $42 \mathrm{mg}$ $473 \mathrm{~g}^{-1} \mathrm{dw}$ to $5 \mathrm{mg} \mathrm{g}^{-1} \mathrm{dw}$.

474 The optimal parameter estimates and the identifiability of the 475 nine model parameters for D. parva are given in Figure 7 and 476 Table 2 . Whereas in the $D$. salina growth model all parameters 477 were identifiable, in the $D$. parva growth model one parameter 478 was practically nonidentifiable, namely the light inhibition 479 coefficient for photosynthetic growth $K_{\mathrm{i}, \mathrm{E}}$. Since $D$. parva 480 showed no pronounced photoinhibitory effects it is biologically 481 plausible that the corresponding parameter $K_{\mathrm{i}, \mathrm{E}}$ is not 482 identifiable indicated by the flat profile likelihood in direction 483 of the upper confidence bound. The halfsaturation coefficient 484 for nitrogen uptake $K_{\mathrm{S}, \mathrm{N}}$ was fixed to a value of $0.155 \mathrm{~g} \mathrm{~m}^{-3}$, 485 which was recalculated from experimental data for Dunaliella 486 tertiolecta from Lomas and Glibert ${ }^{16}$ and has already been used 487 for the growth model published by Fachet et al. ${ }^{8}$ The 488 confidence intervals calculated for the parameters $K_{\mathrm{S}, \mathrm{N}}$ and $489 K_{\mathrm{i}, \mathrm{E}}$ are higher for $D$. parva compared to $D$. salina. This 490 illustrates the strength of the profile likelihood analysis in 491 comparison to the frequently used likelihood analysis in which 492 one parameter is varied and the remaining parameters are kept 493 constant. Large confidence intervals in the profile likelihood 494 result from structural dependencies between different model 495 parameters. For this reason, the profile likelihood derived 496 confidence intervals are much more informative with regard to 497 (i) identifiability, (ii) detection of (nonlinear) parameter 498 interdependencies, and (iii) consistency in confidence interval 499 estimates compared to likelihood derived (individual) con500 fidence intervals. This also holds for classical Hessian-based 501 estimates of confidence intervals, which only yield consistent 502 approximations for identifiable parameters.

503 In agreement with the PAM measurements (Figures 1a,b) for 504 which $D$. parva showed a significantly higher ETR compared to 505 D. salina, the better photosynthetic growth potential is also 506 reflected by the parameter estimates for the maximal growth 507 rate $\left(\mu_{\max }\right)$ and the half saturation coefficient for photosynthetic 508 growth $\left(K_{\mathrm{s}, \mathrm{E}}\right)$ as shown in Table 2 . The optimal parameter 509 estimates obtained for $D$. parva are notably higher compared to 510 D. salina, namely 6.980 to $1.708 \mathrm{~d}^{-1}$ for $\mu_{\max }$ and 0.396 to 0.033 511 mol photons $\mathrm{m} \mathrm{g}^{-1} \mathrm{dw} \mathrm{d}{ }^{-1}$ for $K_{\mathrm{s}, \mathrm{E}}$. Because of the small cell 512 weight of $D$. parva (Table $\mathrm{S} 1$ ), the higher photosynthetic 513 growth potential does not translate into a more productive 514 cultivation process since the biomass productivity of D. parva is 515 considerably lower compared to that of $D$. salina (see Table 516 S5). However, the strain selection of D. parva for an outdoor 517 cultivation process might be beneficial because of its absence of 518 photoinhibition under high irradiance.

519 In this work, the $\beta$-carotene content under HL-ND 520 conditions for $D$. salina was $80 \mathrm{mg} \mathrm{g}^{-1} \mathrm{dw}, 63 \%$ higher than 521 the $49 \mathrm{mg} \mathrm{g}^{-1} \mathrm{dw}$ measured for $D$. parva. Therefore, also the 522 parameter for the light stress-induced $\beta$-carotene synthesis rate $523 r_{\text {car, } \mathrm{E}}$ is 2-fold higher for D. salina (0.032 $\mathrm{g} \mathrm{Car} \mathrm{g}^{-1} \mathrm{dw} \mathrm{d}^{-1}$ to $5240.016 \mathrm{~g} \mathrm{Car} \mathrm{g}^{-1} \mathrm{dw} \mathrm{d}^{-1}$ for D. parva). However, the critical light 525 intensity for $\beta$-carotene synthesis $\left(E_{\text {car,crit }}\right)$ is almost comparable 526 (70 mol photons $\mathrm{g}^{-1} \mathrm{dw} \mathrm{d} \mathrm{d}^{-1}$ for D. parva and $78 \mathrm{~mol}$ photons $527 \mathrm{~g}^{-1} \mathrm{dw} \mathrm{d} \mathrm{d}^{-1}$ for D. salina).

\section{$528 \square$ CONCLUSIONS}

529 In this work, a systematic approach for analysis of interspecies 530 variability with the case study of $\beta$-carotene production in the 531 Dunaliella species D. salina and D. parva in a photobioreactor 532 setup was presented. The results of the experimental comparison indicated significant variability between $D$. salina 533 and $D$. parva in terms of morphological differences, the 534 biomass, and $\beta$-carotene productivity as well as differences in 535 photoacclimation and photoinhibition. The experimental data 536 was used to formulate a dynamic-kinetic model. The ordinary 537 differential equation system accounted for biomass growth, 538 nutrient uptake, and pigment fraction in the biomass and was 539 able to describe the both species in a good manner. The 540 proposed model structure was a trade-off between the 541 justification of the experimentally observed behavior under 542 various abiotic stress conditions with a minimal number of 543 parameters. In agreement with the experimental results, the 544 optimal parameter values estimated for D. salina and D. parva 545 showed significant interspecies deviations. The profile like- 546 lihood analysis demonstrated that the majority of the model 547 parameters were structurally and practically identifiable giving 548 evidence of its predictivity. The ongoing methodological 549 advances in the experimental as well as the computational 550 area will further broaden our knowledge on the metabolic 551 adaption of microalgae and lead to a progressive improvement 552 of mathematical models. Thereby, the engineering of 553 industrially valuable strains is accelerated and provides the 554 basis for effective bioprocess design with photosynthetic 555 microorganisms.

\section{ASSOCIATED CONTENT}

\section{S Supporting Information}

558

The Supporting Information is available free of charge on the 559 ACS Publications website at DOI: 10.1021/acs.iecr.7b01423. 560

Overview of experimental conditions; biotechnological 561 performance of $D$. salina and D. parva; model equations; 562 overview of parameters from dynamic-kinetic model 563 (PDF)

\section{AUTHOR INFORMATION}

\section{Corresponding Author}

*E-mail: rihko@mpi-magdeburg.mpg.de.

\section{ORCID $(1)$}

Liisa K. Rihko-Struckmann: 0000-0003-0222-7236

Notes

The authors declare no competing financial interest.

\section{ACKNOWLEDGMENTS}

This research work was partly supported by the Center for 573 Dynamic Systems (CDS) in Magdeburg/Germany, funded by 574 the EFRE funds of the German Federal State Saxony-Anhalt. 575 The authors gratefully thank Anne Christin Reichelt and 576 Markus Ikert for their technical support in pigment extraction 577 and detection as well as Isabel Harriehausen for supporting the 578 cultivations, the flow cytometric analysis, and the PAM 579 measurements.

\section{REFERENCES}

581

(1) Polle, J. E. W.; Tran, D.; Ben-Amotz, A. In The Alga Dunaliella: 582 Biodiversity, Physiologoy, Genomics and Biotechnology, 1st ed.; Ben- 583 Amotz, A., Polle, J. E. W., Rao, D. V. S., Ed.; Science Publishers: 584 Enfield, 2009; Chapter 1, pp. 1-13.

(2) Ben-Amotz, A.; Shaish, A.; Avron, M. The biotechnology of 586 cultivating Dunaliella for production of $\beta$-carotene rich algae. Bioresour. 587 Technol. 1991, 38, 233-235.

588

(3) Gonzalalez, M. A.; Gomez, P. I.; E. W. Polle, J. In The Alga 589 Dunaliella: Biodiversity, Physiologoy, Genomics and Biotechnology, 1st ed.; 590 
591 Ben-Amotz, A., Polle, J. E. W., Rao, D. V. S., Ed.; Science Publishers; 592 Enfield, 2009; Chapter 2, pp. 15-43.

593 (4) Lichtenthaler, H. K. Current Protocols in Food Analytical 594 Chemistry; Wiley, 2001.

595 (5) Fachet, M.; Hermsdorf, D.; Rihko-Struckmann, L.; Sundmacher, $596 \mathrm{~K}$. Flow cytometry enables dynamic tracking of algal stress response: A 597 case study using carotenogenesis in Dunaliella salina. Algal Res. 2016, 598 13, 227-234.

599 (6) Borowitzka, M. A.; Siva, C. J. The taxonomy of the genus 600 Dunaliella (Chlorophyta, Dunaliellales) with emphasis on the marine 601 and halophilic species. J. Appl. Phycol. 2007, 19, 567-590.

602 (7) Schreiber, U.; Klughammer, C.; Kolbowski, J. PAM Application 603 Notes 2011, 1, 1-21.

604 (8) Fachet, M.; Flassig, R. J.; Rihko-Struckmann, L.; Sundmacher, K. 605 A dynamic growth model of Dunaliella salina: Parameter identification 606 and profile likelihood analysis. Bioresour. Technol. 2014, 173C, 21-31. 607 (9) Mairet, F.; Bernard, O.; Lacour, T.; Sciandra, A. Modelling 608 microalgae growth in nitrogen limited photobiorector for estimating 609 biomass, carbohydrate and neutral lipid productivities. Preprints of the 610 18th IFAC World Congress 2011, 44, 10591-96.

611 (10) Droop, M. R. Vitamin B12 and Marine Ecology. IV. The 612 Kinetics of Uptake, Growth and Inhibition in Monochrysis Lutheri. J. 613 Mar. Biol. Assoc. U. K. 1968, 48, 689-733.

614 (11) Hindmarsh, A. C.; Brown, P. N.; Grant, K. E.; Lee, S. L.; Serban, 615 R.; Shumaker, D. E.; Woodward, C. S. Acm Transactions on 616 Mathematical Software 2005, 31, 363-396.

617 (12) Raue, A.; Kreutz, C.; Maiwald, T.; Bachmann, J.; Schilling, M.; 618 Klingmüller, U.; Timmer, J. Structural and practical identifiability 619 analysis of partially observed dynamical models by exploiting the 620 profile likelihood. Bioinformatics 2009, 25, 1923-1929.

621 (13) Kreutz, C.; Raue, A.; Kaschek, D.; Timmer, J. Profile likelihood 622 in systems biology. FEBS J. 2013, 280, 2564-2571.

623 (14) Hein, M.; Pedersen, M. F.; Sand-Jensen, K. Size-dependent 624 nitrogen uptake in micro- and macroalgae. Mar. Ecol.: Prog. Ser. 1995, $625118,247-253$.

626 (15) Lamers, P. P.; Janssen, M.; De Vos, R. C. H.; Bino, R. J.; 627 Wijffels, R. H. Carotenoid and fatty acid metabolism in nitrogen628 starved Dunaliella salina, a unicellular green microalga. J. Biotechnol. 629 2012, 162, 21-27.

630 (16) Lomas, M. W.; Glibert, P. M. Comparisons of Nitrate Uptake, 631 Storage, And Reduction in Marine Diatoms and Flagellates. J. Phycol. 632 2000, 36, 903-913.

633 (17) Muñoz-Tamayo, R.; Martinon, P.; Bougaran, G.; Mairet, F.; 634 Bernard, O. Getting the most out of it: Optimal experiments for 635 parameter estimation of microalgae growth models. J. Process Control 636 2014, 24, 991-1001.

637 (18) Flassig, R. J.; Migal, I.; der Zalm, E. v.; Rihko-Struckmann, L.; 638 Sundmacher, K. Rational selection of experimental readout and 639 intervention sites for reducing uncertainties in computational model 640 predictions. BMC Bioinf. 2015, 16, 13. 